\title{
Psychiatric disorder among children at time of entering local authority care: questionnaire survey
}

\author{
G Dimigen, C Del Priore, S Butler, S Evans, L Ferguson, M Swan
}

Grave concern has been voiced about the high rate of psychiatric disorders among children in the care system. ${ }^{1-4}$ This concern is based on observations of children who have been looked after and accommodated for a considerable length of time. McCann and colleagues, for example, looked at the prevalence of mental illness in adolescents who had been in care on average for 2.9 years. ${ }^{2}$ Little is known, however, about the mental health of children at the time they enter local authority care. We aimed to gain information about children's mental health at this stage of their care, with a view to planning an early intervention programme.

\section{Method and results}

The study was carried out in Glasgow from August 1996 to June 1997. It targeted children aged between 5 years and 12 years who attended for health assessment within six weeks of admission into care. During the study period 89 children attended for health assessment. The accompanying carer was given the Devereux scales of mental disorders ${ }^{5}$ and was asked to return the questionnaire by post to the investigators. Seventy completed questionnaires were returned, a response rate of $79 \%$. Thirty four questionnaires were for boys, 36 for girls; 26 children were taken into residential units, 44 into foster care. The mean age of the children was 9.6 years.

The Devereux scales of mental disorders assess behaviour according to the categories given in the third edition (revised) and the fourth edition of the Diagnostic and Statistical Manual of Mental Disorders. The scales investigate conduct and attention disorders, anxiety, depression, autistic-like detachment, and acute problems. The responses are converted into $\mathrm{T}$ scores, with a mean of 50 and a standard deviation of 10 . All T scores are calculated by age group and sex. The Devereux scales provide qualitative descriptions of the T scores: "very elevated" (more than 2 SD above the mean), "elevated" (1-2 SD above the mean), "borderline," (T score 56-59) and "average" (T score $\leqslant 55$ ).

The figure shows the percentage of children across the six Devereux subscales in the four descriptive categories. The expected population values as provided by the Devereux scales are also shown. The most common disorders among the children were conduct disorder and depression. Thirteen (38\%) boys and 12 $(33 \%)$ girls showed very elevated levels of conduct disorder. Very elevated levels of depression were significantly more common among children in residential establishments than among foster children (13 (50\%) v 12 (27\%); $\mathrm{P}<0.05)$. Twenty one $(30 \%$; $95 \%$ confidence interval $19 \%$ to $41 \%$ ) of the children had severe attention difficulties and $18(26 \% ; 16 \%$ to $36 \%)$ had autistic-like detachment. Fewer children had very elevated levels of acute problems ( $15(21 \% ; 11 \%$ to $31 \%)$ ) or anxiety disorders (11 (16\%; $7 \%$ to $25 \%)$. Comorbidity was found in over a third of the children

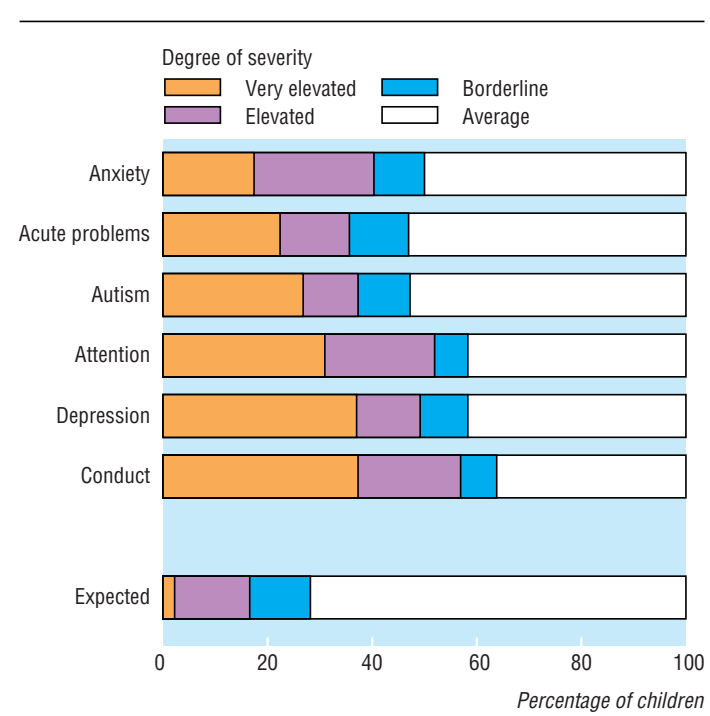

Prevalence of mental disorders among 70 children at time of entering local authority care, according to Devereux scales of mental disorders (see methods for description of scales)

(27 obtained a score of $\geqslant 70$ on more than one subscale).

\section{Comments}

These findings show a worrying gap in mental healthcare provision. The study shows that a considerable proportion of young children have a serious psychiatric disorder at the time they enter local authority care but are not being referred for psychological help. We believe that these findings strongly indicate the need for early intervention policies to help this vulnerable group. Furthermore, the complex needs of these children can only be assessed effectively through multidisciplinary discussion and strategic planning.

Funding: Yorkhill NHS Trust (Department of Clinical Psychology) and Greater Glasgow Health Board.

Competing interests: None.

Contributors: GD discussed core ideas, analysed and interpreted data, and wrote the paper. CDP and SB initiated the research, planned and designed the study, and discussed core ideas. SE facilitated the planning and execution of the survey and gave access to her patients. LF participated in data collection and initial data analysis. MS contributed to the writing and editing of the paper. GD is the guarantor.

1 Bamford F, Wolkind SN. The physical and mental health of children in care research methods. London: Economic Research Council, 1988.

2 McCann JB, James A, Wilson S, Dunn G. Prevalence of psychiatric disorders in young people in the care system. BMJ 1996;313:1529-30.

3 Polany L, Glaser A, Rao V. Better health for children in residence care Arch Dis Child 1996;75:263-5.

4 Wolkind S, Rushton A. Residential and foster family care. In: Rutter M, Taylor E, Hersov L, eds. Child and adolescent psychiatry. Oxford: Blackwell Taylor E, Hersov L, eds.
Scientific,1994:252-66.

5 Naglieri JA, LeBuffe PA, Pfeiffer SI. The Devereux scales of mental disorders. New York: Harcourt Brace, 1993.

(Accepted 9 June 1999)
Department of

Psychology,

University of

Glasgow, Glasgow

G12 8RT

G Dimigen

senior lecturer

Royal Hospital for Sick Children,

Yorkhill NHS Trust,

Glasgow G3 8SJ

C Del Priore

head of clinical

psychology services

L Ferguson

assistant clinical

psychologist

M Swan

assistant clinical

psychologist

Community Child

Health, Yorkhill

NHS Trust

S Butler

consultant clinical

psychologist

Springburn Health

Centre, Glasgow

G21 1TR

S Evans

consultant community

paediatrician

Correspondence to:

Dr Dimigen

G.Dimigen@psy.

gla.ac.uk

BMJ 1999;319:675 